\title{
Supervisory Incentives and Credit Portfolio Management: A Field Experiment and Findings
}

\author{
Angbonon Eugene Kamalan* \\ Department of Economics, Alassane Ouattara University, 28, BP 1694 Abidjan 28, Ivory Coast
}

\begin{abstract}
An agency problem regarding moral hazard of individual borrowers within lending contracts is efficiently addressed with supervisory practices, especially sponsorship and endorsement that lead to selecting the optimal project (with higher expected return and lower risk) and the optimal control of borrowers. According to a recent study, there is a liability constraint of the endorsement that plays as an incentive mechanism for better projects selecting and an incentive constraint of the sponsorship that plays for better monitoring of borrowers, (Kamalan, 2018). Although the conclusions are very relevant in economics with a broad range of applications in management field, especially in marketing, the results of the modelling remain theoretical. The overall objective of this study is to analyze the effectiveness of incentive mechanisms on maturity repayment behavior of borrowers and the time of exposure to default. Specifically, the article aims at testing empirically the causal effects of supervisory practices within lending contracts with a focus on the maturity repayment behavior of borrowers.
\end{abstract}

First, we test the influence of supervisory incentives on the borrower's behavior regarding maturity repayment with Logistic and Poisson regression. Second, we analyze the effects of supervisory incentives on credit' life-time of borrowers with Kaplan-Meier and Cox regression.

The findings attest that supervisory incentives are significantly powerful to lead borrowers to better maturity repayment behavior. The resulting model is significant to introduce into the search for the determinants of categories of "best" customers in maturity repayment and adversely, those mostly considered as vulnerable to delays that will lead to a real strategy of portfolio management.

Keywords: Principal-Supervisor-Agent, Incentives, Logit, Poisson regression, Survival analysis, Censoring, Cox regression

JEL Codes: C14, C24, C25, C41, D91

DOI: $10.7176 / \mathrm{EJBM} / 11-12-25$

Publication date: April $30^{\text {th }} 2019$

\section{Introduction}

Supervisory practices are defined as social relations networks and better known as non-market institutions within contracts. Since behavioral economists invite to the understanding of the complex economic and behavioral factors (known as non-market institutions) that affect the decisions of individuals within contracts, the understanding of the role of social relations networks within contracts has become a topic of increasing interest. There are pioneering works with Stiglitz (1974) on tenant farming, pursued by Laffont and Matoussi (1995) and renewed by Bidisha and al. (2018). It also concerns the gift-exchange and market nexus (Akerlof, 1982), extended by Bryson and Freeman (2018). Consequently, the impact of non-market institutions in terms of contract efficiency has been a topic of increasing interest in the theories of contracts, regarding transaction costs, property rights, incomplete contracts and agency relationships.

To a better understanding of the role of such non-market institutions within contracts, a relevant method based on the principal-agent paradigm is largely used and address many topics: organization (Ashraf and Bandiera, 2018), management of public goods such as environment (Smith, 2018), etc. A specific concern is devoted to exploring the conditions of effectiveness of lending contracts and this concern is being raised by alternative banking firms such as cooperatives (Banerjee, Besley and Guinnane, 1994; Besley, 1995) and microfinance institutions (Stiglitz, 1990; Varian, 1990; Besley and Coate, 1995, Armendariz de Aghion and Gollier, 2000). In the studies, the neighborhood is supposed to have better information about borrowers and can thus exercise more effective control over them. In a context where information asymmetry (adverse selection and moral hazard) can degrade lending relationships, the commitment of the borrower's acquaintances can be used to solve such an information problem. This is the principle of peer review, first analyzed by Varian and then Stiglitz. These studies unanimously maintain 
that taking peer review into account makes it possible to bring out non-opportunistic behaviors through solidarity guarantees, the possibility of social sanctions and long-term interactions. Peer review is then modelled as supervisor in a Principal-Supervisor-Agent model.

Supervisory practices such as endorsement and sponsorship are, in this case, incentive devices that encourage the effort of borrower to not engage in too risky projects, Kamalan (2018) and then are seen as being important tool for reducing loan delinquency, (Cassar, Crowley and Wydick, 2007). Supervisory practices are shown theoretically to be a way of acquiring information on creditworthiness for reducing default risk, (Stiglitz, 1990), (Armendariz de Aghion and Gollier, 2000).

In a model composed of a Principal, a Supervisor and an Agent such as the one developed by Banerjee, Besley and Guinnane (1994), supervisors are likely to have efficient effects on the agent's behaviors due to the incentives that supervisors provide.

The contribution of this article is to take into account supervisory practices known as sponsorship and endorsement within lending contracts, in order to questioning their effect in solving agency problem of moral hazard of borrowers, especially, in testing the effects of those practices on the maturity repayment of borrowers. As proposed in Kamalan (2019), we consider the lending institution (microfinance for example) as the Principal. The Supervisor is a no borrowing member of the same loan. It does not refer to joint liability member. The Endorsers and/or sponsors are considered supervisors engaged in the lending contracts. An endorser is known as a third party who provides a real collateral (salary for example) in return to the debt the borrower receives. According to a recent study, there is a liability constraint of the endorsement that plays as an incentive mechanism for better projects selecting (Kamalan 2018), and the sponsorship given by third parties plays for better monitoring of borrowers. The borrower is considered to be the Agent. Finally, a loan is represented by twelve monthly maturities and the number of maturities per borrower represents his/her total credit life time.

Our analytical model is based on the framework of Bénabou and Tirole (2003). The authors analyze the effects of incentives on individuals' behavioral supply in the short and long term. This framework uses the principal-agent paradigm with asymmetric information. However, our study, which is intended to be applied, differs significantly from Bénabou and Tirole (Op. Cit.) in terms of mathematical modelling.

In our study, we will analyze the effects of incentive mechanisms on borrowers' repayment behavior and on the credit' life-time in four steps. First, we use a Logistic model to test the impact of supervisory practices on the probability of maturity repayment without failure for all borrowers. Second, we use Poisson regression analysis to test the impact of supervisory practices on the frequency of delays occurring in the repayment of maturities by loan borrowers with at least one delay. The number of delays is modelled as occurring at the frequency defined by a Poisson test, based on predictors. Third, we use the duration or survival analysis for the modelling of failures and credit' life-time of borrowers. Credit' life-time is modelled with the Kaplan-Meier graphs that provides failure estimates. Last, we use the Cox regression analysis to test the risk of default.

The article is organized as follows. Section 2 presents the data, the methodological approach and model estimations. Section 3 provides the main findings and section 4 gives some concluding remarks.

\section{Data, methods and model estimations}

\subsection{Data and variables}

The data used in the econometric study of this article come from a survey conducted in Cotonou, (Benin, West Africa), in 2006. The study uses cross-sectional data from a sample of 832 borrowers. The sample includes 506 individual loans borrowers, and 272 group loans, covering the population of 21146 customers in a microfinance institution called PADME in Cotonou (Note 1). The survey includes only borrowers in process of credit. We've developed a questionnaire submitted to the 832 people in the sample. We obtained several data concerning the loan relationship with the lending institution. We've produced from these data the variables of the study.

The variables of the study are presented as follows. The dependent variables concern: 1-the delay (delay), it's a binary variable that takes the value 1 for borrowers who have no delay and 0 for those who have at least one delay; 2-the number of delays (nbr_delays) from 0 to 13 and 3-the number of maturities (maturities) from 0 to 132. (Note 2). The explanatory variables are:

- collateral: the type of collateral proposed by borrowers (plots, plots and other collateral, vehicles, salary, no real collateral). No real collateral refers to personal collateral i.e. the presence of supervisors.

- penalty: the assessment of the penalty amount (acceptable, low, too high)

- gift: receiving a gift (having received a gift, not having received a gift) 
- amount: the assessment of the received amount (acceptable, not satisfying)

- sponsorship: the sponsorship status (sponsored, not sponsored)

- education: education level (illiterate, primary, secondary, university)

- loan_renewal: loan renewal (wishes for renewal; does not wish for new loan)

- work: the main work (trade, agriculture and livestock, crafts and processing, service, worker for public/private)

\subsection{Methodological approaches and model estimations}

\subsubsection{Logistic regression of default}

Let us consider that delay occurs randomly. Using the Logit model, we determine the factors that may explain the non-default of borrowers. This model is particular in explaining discrete variables that have two modalities. It provides the parameters of independent variables. It also provides the elasticity $(\mathrm{dy} / \mathrm{dx})$ consisting in the probability of the marginal effects. That indicates the change in the dependent variable relating to the move from the baseline modality of an independent variable to a specific study modality. The Logit model used is as follows:

$$
\begin{aligned}
& \text { Logit Delay } i_{-}=C 0+C 1 \text { collateral }_{-} i j+C 2 \text { penalty }_{-} i j+C \text { gift }_{-} i j+C 4 \text { amount }_{-} i j+C 5 \text { sponsorship }_{-} i j
\end{aligned}
$$

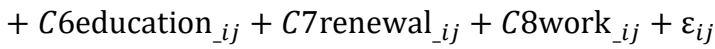

$i=1, \ldots n$ and $j=1, \ldots J$

Table 1. Marginal effects of Logistic regression

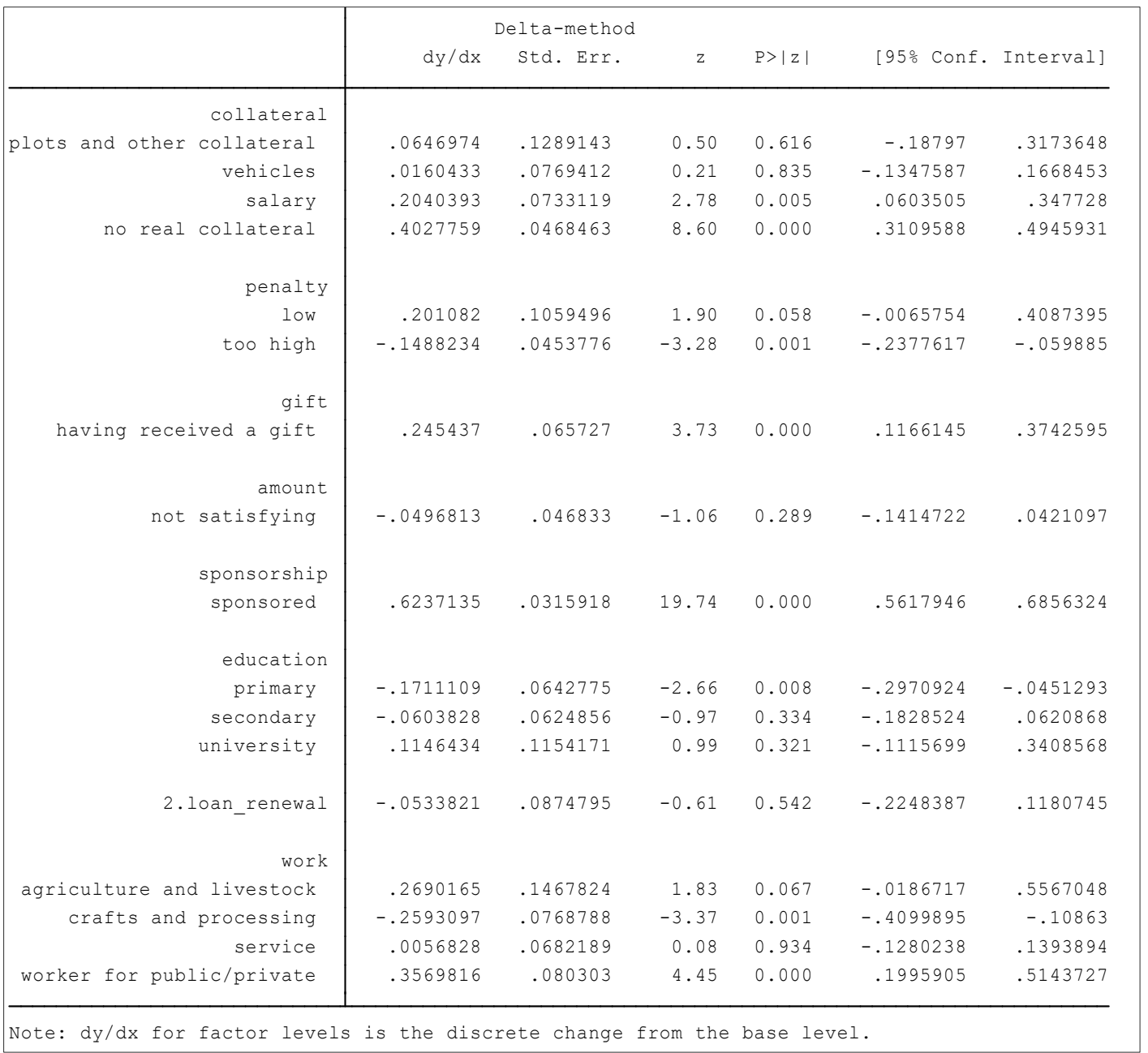

Author' calculation 
Once the factors that significantly explain the non-failure behavior are known, we focus on the way factors determine the frequency of failures. We use the Poisson model to count the number of delays (nbr_delays) made by borrowers who have experienced at least one default in the maturity repayments.

\subsubsection{Poisson regression of the number of delays}

The models to be estimated are:

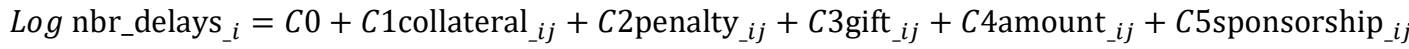

$$
\begin{aligned}
& + \text { C6education }_{-} i j+C 7 \text { renewal }_{-} i j+C 8 \text { work }_{\_} i j+\varepsilon_{i j}
\end{aligned}
$$

Frequency of delays ${ }_{-}$

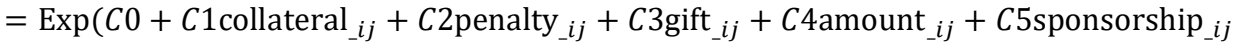

$$
\begin{aligned}
& \left.+ \text { C6education }_{-} i j+C 7 \text { renewal }_{-} i j+C 8 \text { work }_{-i j}+\varepsilon_{i j}\right)
\end{aligned}
$$

Table 2. Parameters of the Poisson regression model

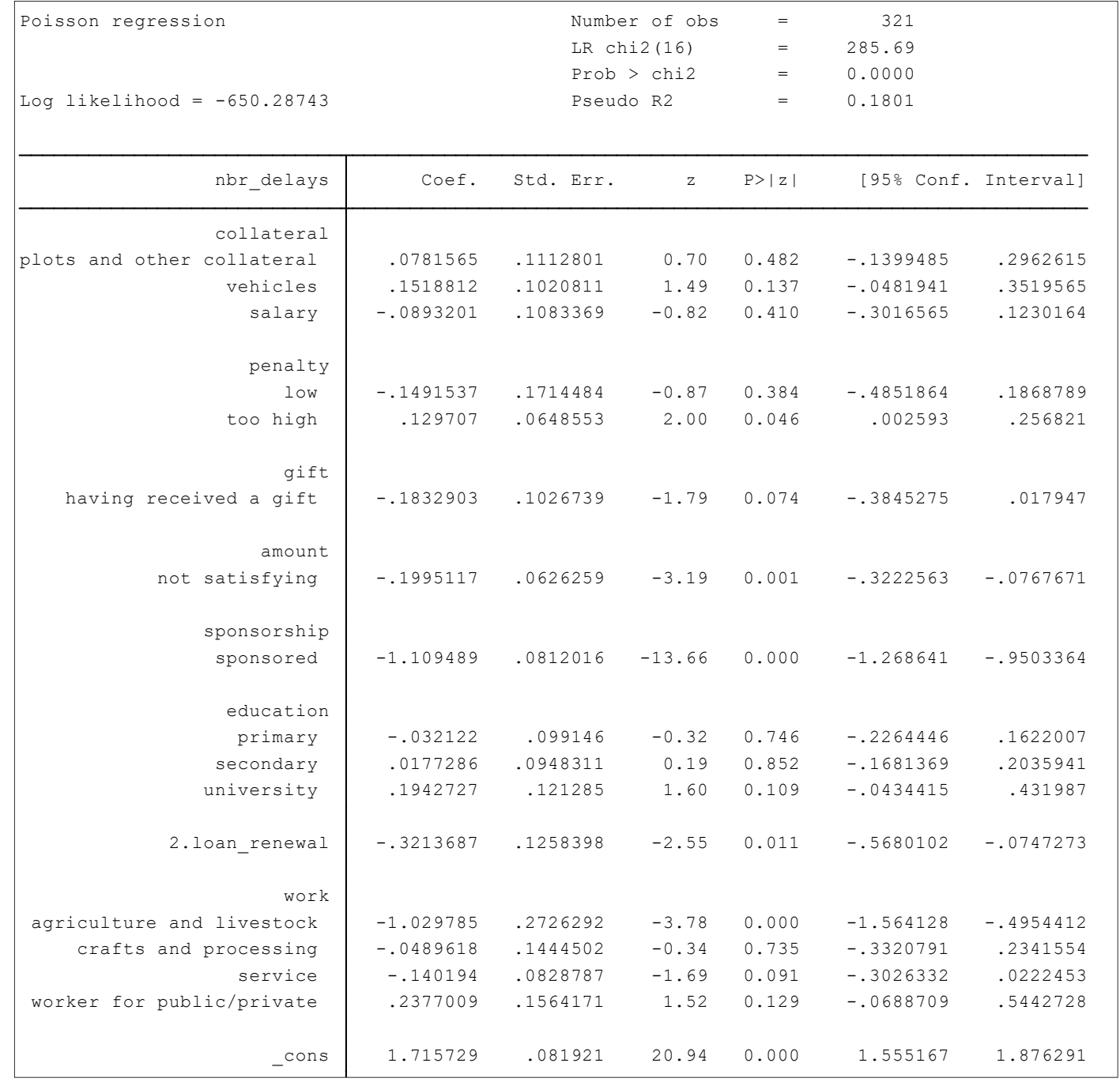

Author' calculation 


\subsubsection{Failure estimate and survival analysis}

Consider three maturities times: $t^{\prime \prime}, t^{\prime}$ and $t$, such that $t^{\prime \prime}<t^{\prime}<t$. The probability of a failure $x$ occurring after time $t$, is written:

$P(x>t)=P\left(x>t^{\prime}, x>t\right) ; P(x>t)=P\left(x>t \mid x>t^{\prime}\right) x P\left(x>t^{\prime}\right)$

$P(x>t)=P\left(x>t \mid x>t^{\prime}\right) x P\left(x>t^{\prime} \mid x>t^{\prime \prime}\right) x P\left(x>t^{\prime \prime}\right)$

The delay (failure) times are distinct $T_{(i)}(i=1, \ldots, n)$ and ranked in ascending order.

$P\left(x>T_{(j)}\right)=\prod_{k=1}^{j} P\left(x>T_{(k)} \mid x>T_{(k-1)}\right)$

When $T_{(0)}=0$, we have:

$Y_{i}$ : the number of borrowers who may be defaulting just before the time $T_{(i)}$ $d_{i}$ : the number of "dead" borrowers, i. e. excluded from the loan portfolio at $T_{(i)}$.

Then the $p_{i}$ probability that a borrower will be removed from the loan portfolio in the interval $\left|T_{(i-1)}, T_{(i)}\right|$, knowing that he was executing credit at $T_{(i-1)}$; i.e. $p_{i}=P\left(x \leq T_{(i)} \mid x>T_{(i-1)}\right)$

is estimated by:

$\widehat{P_{l}}=\frac{d_{i}}{Y_{i}}$
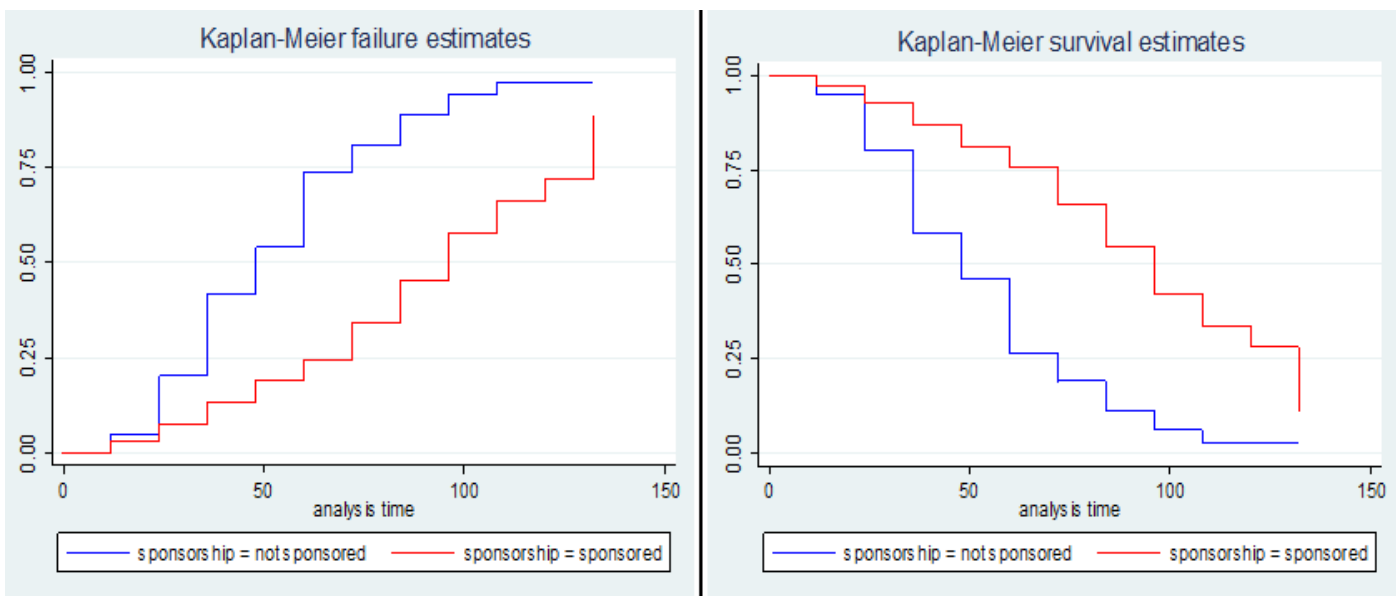

Figure 2: Kaplan-Meier failure and survival estimates with predictor Sponsorship 
Table 3. Kaplan-Meier failure Table

Author' calculation

\begin{tabular}{|c|c|c|c|c|c|c|c|}
\hline & Beg. & & Net & Failure & std. & & \\
\hline Time & Total & Fail & Lost & Function & Error & Conf. & Int.] \\
\hline \multicolumn{8}{|c|}{ not sponsored } \\
\hline 12 & 322 & 16 & 5 & 0.0497 & 0.0121 & 0.0307 & 0.0798 \\
\hline 24 & 301 & 48 & 13 & 0.2012 & 0.0225 & 0.1612 & 0.2497 \\
\hline 36 & 240 & 65 & 17 & 0.4176 & 0.0282 & 0.3646 & 0.4749 \\
\hline 48 & 158 & 33 & 6 & 0.5392 & 0.0292 & 0.4832 & 0.5973 \\
\hline 60 & 119 & 51 & 2 & 0.7367 & 0.0267 & 0.6832 & 0.7876 \\
\hline 72 & 66 & 18 & 4 & 0.8085 & 0.0242 & 0.7589 & 0.8534 \\
\hline 84 & 44 & 18 & 0 & 0.8868 & 0.0202 & 0.8438 & 0.9225 \\
\hline 96 & 26 & 12 & 5 & 0.9391 & 0.0155 & 0.9038 & 0.9647 \\
\hline 108 & 9 & 5 & 0 & 0.9729 & 0.0122 & 0.9407 & 0.9901 \\
\hline 132 & 4 & 0 & 4 & 0.9729 & 0.0122 & 0.9407 & 0.9901 \\
\hline \multicolumn{8}{|c|}{ sponsored } \\
\hline 12 & 510 & 15 & 68 & 0.0294 & 0.0075 & 0.0178 & 0.0483 \\
\hline 24 & 427 & 20 & 87 & 0.0749 & 0.0122 & 0.0543 & 0.1029 \\
\hline 36 & 320 & 20 & 30 & 0.1327 & 0.0170 & 0.1030 & 0.1700 \\
\hline 48 & 270 & 18 & 59 & 0.1905 & 0.0206 & 0.1537 & 0.2348 \\
\hline 60 & 193 & 13 & 42 & 0.2450 & 0.0241 & 0.2014 & 0.2962 \\
\hline 72 & 138 & 18 & 24 & 0.3435 & 0.0301 & 0.2881 & 0.4062 \\
\hline 84 & 96 & 16 & 14 & 0.4529 & 0.0354 & 0.3866 & 0.5250 \\
\hline 96 & 66 & 15 & 16 & 0.5773 & 0.0393 & 0.5018 & 0.6549 \\
\hline 108 & 35 & 7 & 4 & 0.6618 & 0.0425 & 0.5785 & 0.7435 \\
\hline 120 & 24 & 4 & 0 & 0.7182 & 0.0438 & 0.6306 & 0.8002 \\
\hline 132 & 20 & 12 & 8 & 0.8873 & 0.0355 & 0.8070 & 0.9448 \\
\hline
\end{tabular}

Table 4. Kaplan-Meier survival Table

\begin{tabular}{|c|c|c|c|c|c|c|c|}
\hline Time & $\begin{array}{r}\text { Beg. } \\
\text { Total }\end{array}$ & Fail & $\begin{array}{l}\text { Net } \\
\text { Lost }\end{array}$ & $\begin{array}{l}\text { Survivor } \\
\text { Function }\end{array}$ & $\begin{array}{c}\text { Std. } \\
\text { Error }\end{array}$ & Conf. & Int. ] \\
\hline \multicolumn{8}{|c|}{ not sponsored } \\
\hline 12 & 322 & 16 & 5 & 0.9503 & 0.0121 & 0.9202 & 0.9693 \\
\hline 24 & 301 & 48 & 13 & 0.7988 & 0.0225 & 0.7503 & 0.8388 \\
\hline 36 & 240 & 65 & 17 & 0.5824 & 0.0282 & 0.5251 & 0.6354 \\
\hline 48 & 158 & 33 & 6 & 0.4608 & 0.0292 & 0.4027 & 0.5168 \\
\hline 60 & 119 & 51 & 2 & 0.2633 & 0.0267 & 0.2124 & 0.3168 \\
\hline 72 & 66 & 18 & 4 & 0.1915 & 0.0242 & 0.1466 & 0.2411 \\
\hline 84 & 44 & 18 & 0 & 0.1132 & 0.0202 & 0.0775 & 0.1562 \\
\hline 96 & 26 & 12 & 5 & 0.0609 & 0.0155 & 0.0353 & 0.0962 \\
\hline 108 & 9 & 5 & 0 & 0.0271 & 0.0122 & 0.0099 & 0.0593 \\
\hline 132 & 4 & 0 & 4 & 0.0271 & 0.0122 & 0.0099 & 0.0593 \\
\hline \multicolumn{8}{|c|}{ sponsored } \\
\hline 12 & 510 & 15 & 68 & 0.9706 & 0.0075 & 0.9517 & 0.9822 \\
\hline 24 & 427 & 20 & 87 & 0.9251 & 0.0122 & 0.8971 & 0.9457 \\
\hline 36 & 320 & 20 & 30 & 0.8673 & 0.0170 & 0.8300 & 0.8970 \\
\hline 48 & 270 & 18 & 59 & 0.8095 & 0.0206 & 0.7652 & 0.8463 \\
\hline 60 & 193 & 13 & 42 & 0.7550 & 0.0241 & 0.7038 & 0.7986 \\
\hline 72 & 138 & 18 & 24 & 0.6565 & 0.0301 & 0.5938 & 0.7119 \\
\hline 84 & 96 & 16 & 14 & 0.5471 & 0.0354 & 0.4750 & 0.6134 \\
\hline 96 & 66 & 15 & 16 & 0.4227 & 0.0393 & 0.3451 & 0.4982 \\
\hline 108 & 35 & 7 & 4 & 0.3382 & 0.0425 & 0.2565 & 0.4215 \\
\hline 120 & 24 & 4 & 0 & 0.2818 & 0.0438 & 0.1998 & 0.3694 \\
\hline 132 & 20 & 12 & 8 & 0.1127 & 0.0355 & 0.0552 & 0.1930 \\
\hline
\end{tabular}

Author' calculation

\subsubsection{Hazard Ratio or instant risk of default with Cox regression}

Suppose a borrower defaults over a time interval set to $[0, T]$. Consider $T$ the credit' life-time, which is a random and continuous variable, and $t \geq 0$, a particular value of $T$.

The survival function $S(t)$ representing the probability of surviving after time $t$ is given by:

$S(t)=P(T>t)$. 
The cdf (cumulative distribution function) of the random variable $T$ representing the probability of defaulting before $t$ is defined as follows:

$F(t)=P(T \leq t)=1-S(t)$.

The probability density which represents the probability of defaulting in a small time interval after time $t$ is given by:

$$
f(t)=\lim _{h \rightarrow 0} \frac{P(t \leq T<t+h)}{h}=F^{\prime}(t)=-S^{\prime}(t)
$$

The instant risk (Hazard ratio) for a fixed time $t$, indicates the probability of defaulting in a small time interval after $t$, conditionally to the fact of having survived until time $t$ (i.e. the instant risk of default for those who survived) is:

$$
\lambda(t)=\lim _{h \rightarrow 0} \frac{P(t \leq T<t+h \mid T \geq t)}{h}=\frac{f(t)}{S(t)}=-\ln (S(t))^{\prime}
$$

Table 5. Parameters of Cox regression model

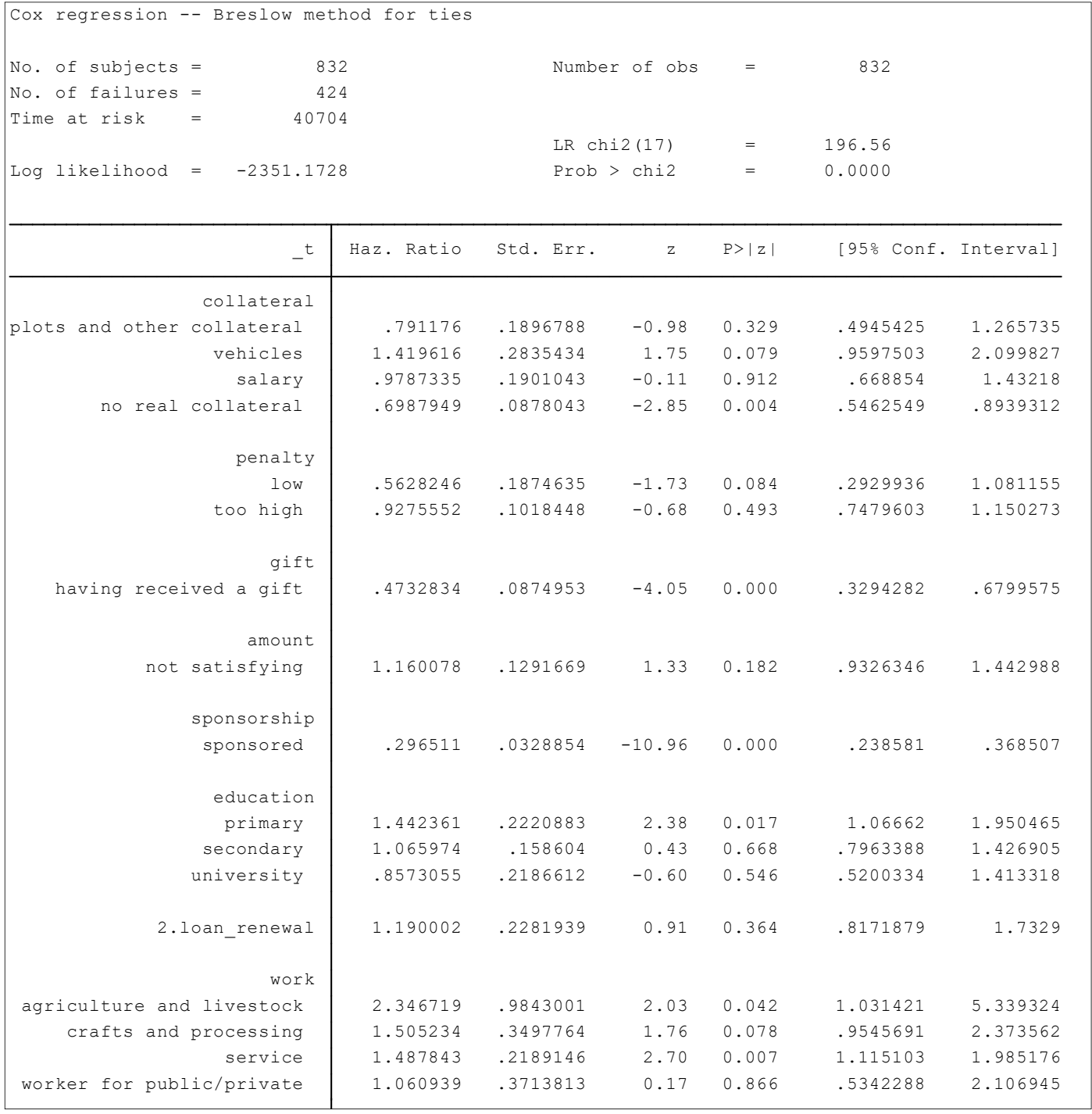

Author' calculation 


\section{Findings}

We performed the following tests to confirm the relevance of our results: the Pearson's test for the Logit model, Pearson's deviance test for the Poisson model, proportional risk test, Wald's test and likelihood ratio test for the Cox model. In addition, we tested the presence of endogeneity and corrected with the instrumental variable method.

\subsection{Effects of supervisory practices on borrower's behavior}

\subsubsection{Effects on maturity repayment behavior with logistic regression}

The estimated Logit model is overall significant. $78.73 \%$ of the non-delay behavior is significantly related to the explanatory variables of the model.

Supervisory practices known as endorsement and sponsorship positively affects borrowers' behavior for not failing maturities. Sponsorship and endorsement highlight the role of personal collateral in loan efficiency. In Table 1, when moving from borrowers who have given a plot of land as collateral to those who gave any real collateral i.e. who proposed supervisors, the probability of not defaulting increases significantly by $40.3 \%$. Sponsorship positively affects borrowers' behavior for non-delay. Moving from a non-sponsored borrower to a sponsored one, the probability of not defaulting increases significantly by $62.4 \%$.

Several other factors have an attractive incentive effect on the maturity repayment behavior without delay. The reward as incentives given by the principal contribute positively to the payment of maturities without any delay by borrowers. Receiving a gift may increase the probability of not defaulting by $24.5 \%$. However, other factors have negative effects on maturity repayment without delay: the primary education level, crafts and proceeding activities, for example.

\subsubsection{Effects on the number of delays with Poisson regression}

The Poisson model estimate highlights the frequency of delays made by borrowers who have defaulted at least once. The deviance test that indicates the adequacy of the Poisson model, provides a deviance probability about $0.0444<0.05$, suitable for reading the results. The results in Table 2 indicate that sponsorship positively reduces the frequency of maturity delayed payment: Coef $=-1.1094$. we've compute the estimated marginal effect that indicates $33.0 \%$ drop in the frequency of defaults from non-sponsored borrowers to sponsored ones.

Other factors are beneficial in reducing the frequency of maturity delayed payment. Rewards are powerful factors that reduce the frequency of maturity delayed payment. In Table 2, incentives in the form of gifts received by borrowers significantly reduce the frequency of delays. The estimated marginal effect indicates $83.2 \%$ drop in the frequency of defaults from borrowers who did not receive a gift to those who did. Similarly, the possibility of credit renewal, the work in agriculture and livestock are significantly leading to the reduction in the frequency of delays in maturity repayments.

\subsection{Effects of supervisory practices in credit' life-time analysis}

\subsubsection{Effects on the failure and survival functions with Kaplan-Meier}

The Figure 1 shows the non-parametric failure and survival estimates with the predictor sponsorship. It describes the trend in borrowers' default and survival according to the sponsorship status. The basic idea is that, when a borrower incurs defaults, he or she gets closer to the end of the credit' life-time. For the Kaplan-Meier non parametric estimator, when a borrower survives a default at maturity time $t$, it means the borrower is alive just before $t$, and he does not die at $t$ time (Note 3). Kaplan-Meier failure and survival estimates are very different while comparing non-sponsored borrowers to those who are sponsored. Non-sponsored borrowers have significantly higher failure rates and are more likely to die faster than sponsored borrowers. Table 3 presents the failure function, which is an estimate of the probability of default by borrowers over time. Time represents the number of maturities.

The failure function evolves less quickly for borrowers who are sponsored. Table 3 shows that, for sponsored borrowers, the average default rate $(50 \%)$ is reached at the 84 th to 96 th maturity dates, i.e. 7 th to 8 th loan. However, for non-sponsored borrowers, the average default rate is quickly reached before the end of the 4th loan. A completely opposite analysis must be done for Table 4 concerning the survival function.

Table 3 and Table 4 provide an important characteristic about right censored observations. An observation is right censored if the person was alive at study termination or was lost to follow-up at any time during the study. Right censoring means that the survival time is only known to exceed a certain value. In this study, survival times are presented to be $12,24, \ldots, 132$. 


\subsubsection{Effects on the instant risk of failure with Cox regression}

To ascertain whether the results of our Cox model are significantly relevant, we performed the following three tests: the proportional risk test, the Wald test and the likelihood ratio test. The results in Table 5 show that each explanatory variable is affected by a hazard ratio, regardless the time period. This ratio indicates the risk of borrowers defaulting at maturity. When borrowers are sponsored, the risk of default given by Haz. Ratio is decreasing and quite low (0.296). When there is no material collateral proposed by the borrowers, i.e. when supervisors exist within the lending contract, the risk of failure becomes significant and decreasing with Haz. Ratio $=0.699$. Conversely, borrowers who offer a vehicle as collateral, those with a primary level of education, those whose main activity is agriculture or livestock, crafts, service activities; are highly vulnerable to maturity defaulting.

\section{Concluding remarks}

The credit repayment behavior of borrowers has always been a key issue for financial institutions. Indeed, this problem is linked to moral hazard, which is made possible by the non-observability of the agent's (borrower's) behavior by the principal (the lending institution). This is reflected in the fact that at maturity, some borrowers do not respect their commitment and gradually drift towards non-payment, which definitively degrades the quality of the credit portfolio. As a result, incentive mechanisms based on the role of supervisors become effective means of encouraging some borrowers to positively change their repayment behavior and reduce their risk of default. These effects are rather significant on the behavior of borrowers who are incentive-sensitive and therefore adopt maturity compliance behavior, while borrowers who are not attracted by such incentives will continue to be highly exposed to default risk.

In this study, we proceeded in different steps to analyze the credit repayment behavior of borrowers. The first two steps, the Logit model and the Poisson model, allowed us to check whether the incentive mechanisms proposed by the supervisors contributed positively and significantly to the borrowers' compliance behavior. Subsequently, we used the Kaplan-Meier and Cox models to analyze the influence of incentive mechanisms on the credit' lifetime.

The findings of this research lead to the following management and business policies for contractual relationships involving a principal and an agent with asymmetric information. 1-The types of incentive mechanisms should be diversified in order to better assess the distinct effects of each incentive mechanism on the change in agents' behaviour. 2-Supervisory incentives are significantly powerful mechanisms for agents' behavior analysis and also appear as dynamic incentives that structurally affect the medium to long-term performance of contracts.

\section{References}

Akerlof, G. (1982), “Labor Contracts as Partial Gift Exchange”, The Quarterly Journal of Economics, 97(4):543569

Armendáriz-de-Aghion, B. \& Gollier, C. (2000), "Peer Group Formation in an Adverse Selection Model", The Economic Journal, 110(465):632-643

Ashraf, N. \& Bandiera, O. (2018), "Social Incentives in Organizations", Annual Review of Economics, Volume 10, 2018, pp 439-463

Banerjee, A., Besley, T. \& Guinnane, T. (1994), “The Neighbor's Keeper: The Design of a Credit Cooperative with Theory and a Test", The Quarterly Journal of Economics, 109(2):491-515

Bénabou, R. \& Tirole, J. (2003), "Intrinsic and extrinsic motivation”, The Review of Economic Studies, 70(3):489520

Besley, T. (1995), "Non market Institutions for credit and risk sharing in low-Income", The Journal of Economic Perspective, 3(9):115-127.

Besley, T., \& Coate, S. (1995), “Group Lending, Repayment Incentives and Social Collateral”, Journal of Development Economics, vol. 46, pp. 1-18.

Bidisha, S., Hossain, A., Alam, R. \& Hasan, M. (2018), "Credit, tenancy choice and agricultural efficiency: Evidence from the northern region of Bangladesh”, Economic Analysis and Policy, Vol.57, pp.22-32

Bryson, A. \& Freeman, R. (2018), “The Role of Employee Stock Purchase Plans, Gift and Incentive? Evidence from a Multinational Corporation”, British Journal of Industrial Relations, Number 007, pages 1-21 
Cassar, A., Crowley, L. \& Wydick, B. (2007), “The Effect of Social Capital on Group Loan Repayment: Evidence from Field Experiments", Economic Journal, 517(117):85-106

Kamalan, E. (2018), "Supervisory incentives within contracts: A principal-supervisor-agent approach", Journal of Finance and Bank Management, 6(2):58-63

Kamalan, E. (2019) "Economic Incentives and Social Norms Can Lead Actors to Prosocial Behavior: An Evidence-Based Framework and Findings", Advances in Politics and Economics, 2(1):23-37

Laffont J.J. \& Matoussi M. (1995), "Moral hazard, financial constraints and sharecropping in El Oulja", The Review of Economic Studies, 62(3):381-399

Smith, S. (2018), "Economic incentives and conservation: Crowding-in social norms in a groundwater commons", Journal of Environmental Economics and Management, Volume 90, July 2018, Pages 147-174

Stiglitz, J. (1974), “Incentives and risk sharing in sharecropping”, Review of Economic Studies 41(2):219-255.

Stiglitz, J. (1990), "Peer monitoring and credit markets", World Bank Economic Review, 4(3):351-366.

Varian, H. (1990), "Monitoring agents with other agents", Journal of Institutional and Theoretical Economics, 146(1):153-174.

Notes

Note 1. PADME was considered to be one of the best microfinance institutions in West Africa with higher repayment rate of borrowers. That lending institution was selected because of the opportunities given to learn about the non-market institutions such as endorsement and sponsorship practices involved in lending contracts.

Note 2. For each maturity, we check if the borrower has repaid the loan before the maturity date. Otherwise, a late payment penalty is imposed. It is therefore the number of penalties that determines the number of delays according to the number of maturities.

Note 3. Death refers to the end of the credit cycle. This means that no longer the lender decides to extend any more credit to the borrower and thus eject him from the loan portfolio. 